\title{
APRENDIZAGEM DA DOCÊNCIA PARA A EDUCAÇÃO BÁSICA EM COMUNIDADES DE PRÁTICA
}

\author{
Joana Paulin Romanowski (PUC/PR)* \\ https://orcid.org/0000-0001-7043-5534 \\ Soraia Carise Prates (UP) ${ }^{* *}$ \\ https://orcid.org/0000-0003-2596-4001 \\ Pura Lucia Oliver Martins (PUC/PR)*** \\ https://orcid.org/0000-0003-0300-8318
}

\section{RESUMO}

O artigo aborda a formação de professores para a educação básica em comunidades de prática, com o objetivo de examinar as contribuições dessas comunidades realizadas em estágio não obrigatório para o aprendizado da docência. Os aportes metodológicos propostos na Teoria Social da Aprendizagem de Wenger (1998) orientam o estudo. A metodologia da pesquisa, de abordagem qualitativa, considera estudo realizado com estudantes de cursos de licenciaturas em uma escola de educação básica. Os dados foram obtidos por meio de registro das reuniões e por relatos dos participantes. Os resultados indicam que a comunidade de prática favorece o aprendizado da docência quanto à organização do ensino e da aprendizagem, identificação de dificuldades de aprendizagem, investigação de procedimentos de atuação no processo de ensino e contribui na constituição da identidade docente.

Palavras-chave: Comunidades de prática. Estágio não obrigatório. Formação de professores da educação básica.

\section{ABSTRACT}

\section{TEACHING LEARNING FOR BASIC EDUCATION IN PRACTICE COMMUNITIES}

The article approaches the teachers education for basic education in communities of practice, with the objective of examining the contributions of this community made in pre-service for the teaching of teaching. The methodology is based on

\footnotetext{
Doutora em Educação pela Universidade de São Paulo (USP). Professora do Centro Universitário UNINTER. Professora Titular da Pontifícia Universidade Católica do Paraná (PUC/PR). Membro do Grupo de Pesquisa Práxis Educativa: Dimensões e Processos, da Pontifícia Universidade Católica do Paraná (PUC/PR). E-mail: joana.romanowski@gmail.com

** Doutora em Educação pela Pontifícia Universidade Católica do Paraná (PUC/PR). Coordenadora e Professora do Curso de Matemática da Universidade Positivo (UP). Membro da Rede Interinstitucional de Pesquisadores e Formação de Professores (RIPEFOR). Participa do Grupo de Pesquisa Múltiplas Conexões da FAE Centro Universitário (FAE/PR). E-mail: soraiacprates@ gmail.com

*** Doutora em Educação pela Universidade de São Paulo (USP). Professora da Pontifícia Universidade Católica do Paraná (PUC/ PR).E-mail: pura.oliver@pucpr.br
} 
the contributions of Wenger's Social Learning Theory (1998). The research methodology, with a qualitative approach, considers a study carried out with undergraduate students in a basic education school. Data were obtained through record of meetings and reports from participants. The results indicate that the community of practice favors to learn the teaching as to organize the teaching and the learning, to identify the learning difficulties, to investigate the procedures of acting in the teaching process and to contribute in the constitution of the teaching identity.

Keywords: Communities of practice. Pre-service. Teachers education.

\section{RESUMEN}

\section{ENSEÑANZA DE APRENDIZAJE PARA LA EDUCACIÓN BÁSICA EN COMUNIDADES DE PRÁCTICA}

El artículo aborda la formación de docentes para la educación básica en comunidades de práctica, con el objetivo de examinar las contribuciones de esta comunidad realizadas en la etapa no obligatoria para aprendizaje de la enseñanza. Las contribuciones metodológicas propuestas en la Teoría del aprendizaje social de Wenger (1998) guían el estudio. La metodología de investigación, con un enfoque cualitativo, considera un estudio realizado con estudiantes de pregrado en una escuela de educación básica. Los datos se obtuvieron a través del registro de reuniones e informes de los participantes. Los resultados indican que la comunidad de práctica favorece el aprendizaje de la enseñanza con respecto a la organización de la enseñanza y el aprendizaje, la identificación de las dificultades de aprendizaje, la investigación de los procedimientos de didáctica en el proceso de enseñanza y contribuye a la constitución de la identidad del profesor.

Palabras clave: Comunidades de práctica. Estagio. Formación de docentes de educación básica.

\section{Introdução}

Os processos de formação inicial de professores para a educação básica têm sido amplamente investigados, como expressam os estados da arte realizados desde os anos de 2000 por André e Romanowski (2002), Romanowski (2002), Brzezinski e Garrido (2006) e Brzezinski (2014). Estes estudos indicam a constituição da formação docente a partir dos currículos dos cursos de licenciatura, acentuando as relações com os conhecimentos e saberes advindos dos diferentes contextos da profissão, nas relações interpessoais, nas experiências individuais e coletivas, no desenvolvimento da autonomia do professor em formação, dentre outros. Notadamente, indicam um volume considerável de estudos em que a relação teoria e prática se expressa dicotomizada e fragmentada. Esses estados da arte indicam que entre os assuntos menos pesquisados está a aprendizagem da docência; o estágio não obrigatório também é pouco investigado, conforme estudos de Prates (2016) e Medeiros (2014).

Este artigo toma por referência a tese defendida por Prates (2016). ${ }^{1}$ A questão central da

1 A pesquisa realizada considerou as normas éticas de investigação com seguintes registros: CAAE: 15252813.0.0000.5573, aprovado no Comitê de Ética, Parecer no 283.335 . 
pesquisa focalizou quais são as contribuições do estágio não obrigatório para a formação docente. Assim, o texto focaliza a aprendizagem da docência para a educação básica efetivada em comunidade de prática, objeto de estudo integrado no bojo da tese já referida.

0 ponto de partida deste artigo considera as seguintes questões: Quais são as aprendizagens da docência oportunizadas com a participação em uma comunidade de prática? A participação em comunidade de prática pode ajudar a formação de estudantes de cursos de licenciatura para a constituição da identidade docente? 0 objetivo é examinar as possibilidades das $\mathrm{Co}^{-}$ munidades de prática no processo de formação de professores para a educação básica.

A realização do estudo em comunidade de prática toma por base as proposições de Wenger (1998), em que as comunidades de prática se constituem grupos de pessoas que compartilham uma preocupação ou uma paixão por algo que fazem e aprendem pela interação com outros sujeitos. Pertencer a comunidades é uma prática constante no cotidiano no compartilhamento de conhecimentos, saberes, experiências de maneira informal e familiar que raramente se pensa nelas como comunidades para o desenvolvimento de aprendizagens profissionais (PRATES, 2016).

Destarte, o texto focaliza a aprendizagem da docência com a finalidade de examinar o interior do estágio não obrigatório. Ao eleger este tempo e espaço, se coloca na berlinda um dos componentes da formação de professores com pouca pesquisa. A modalidade de estágio não obrigatório também parece não estar incluída nas pesquisas que focalizam a formação de professores, o que indica ser necessário ampliar estudos sobre esse tipo de formação, no contexto atual, diante das legislações e demandas que surgem no cotidiano dos sistemas educacionais, que incluem a realização de estágio com cada vez mais intensidade.

0 estudo que orienta este artigo é de abordagem qualitativa em que os dados foram coletados por meio de registro das falas expressas pelos estagiários participantes durante as reuniões da comunidade de prática realizadas em uma escola de educação básica, que será melhor descrita adiante. Assim, o texto está organizado com os fundamentos da Teoria Social da Aprendizagem, inclui considerações sobre o estágio não obrigatório, descreve a metodologia de investigação e finaliza com os resultados e indicações sobre a aprendizagem da docência em comunidades de prática.

\section{A aprendizagem para a docência em comunidades de prática: aportes fundamentais}

Sobre a aprendizagem da docência, Russ, Sherin e Gamoran (2016), em consulta ao Handbook of Research on Teaching, revisaram a literatura internacional em relação ao tema "Aprendizagem de professores". Com essa revisão, eles apontam três abordagens que têm sido tradicionais na pesquisa sobre aprender a ensinar: a abordagem processo-produto, que compreende o aprender a ensinar como processo de aquisição de habilidades e destrezas para atuar sobre a prática; a abordagem cognitiva ou de pensamento do professor, que entende o aprender a ensinar como um processo individual de mudança de atitudes, crenças, conhecimento (especialmente o conhecimento pedagógico do conteúdo); e a abordagem orientada ou socioconstrucionista, que enfatiza os professores como sujeitos que não aprendem sozinhos, mas sim em contexto social. Mais que o aprender a profissão, o professor se responsabiliza e atua para qualificar a ação humana e o acolhimento aos que chegam. Assim tornam-se sujeitos capazes de produzir e potencializar a ação como atividade demasiadamente humana, que se faz por meio da interação (NÖRNBERG, 2018).

Com efeito, a aprendizagem da docência entendida como um processo de interação é uma possibilidade inserida em comunidades de prática. Para Wenger (1998), as comunidades 
de prática constituem um dos elementos que estruturam sua teoria social da aprendizagem. Nessa teoria, a aprendizagem é situada em trajetórias de participação em um mundo social, especificamente no interior da comunidade de prática. A aprendizagem resulta de uma trajetória na qual os sujeitos sofrem mudanças de participação periférica legítima para participação socialmente plena, em tal prática, pela interação que se estabelece e os envolve.

Os autores destacam as oportunidades de aprendizagem em uma comunidade de prática como originadas da movimentação de conhecimentos e práticas entre aprendizes e pares próximos. Mais do que prover ensinamentos, as relações entre os participantes acontecem ao conferir um acesso legítimo à participação na comunidade. Como participantes periféricos, estudantes em formação podem ter uma visão da dimensão do processo em totalidade, o que potencializa a compreensão do que é realizado. Essa compreensão favorece a aprendizagem em uma prática social, assim ocorre uma formação em que todos estão envolvidos no processo. Desse modo, o processo formativo vai se constituindo e se cumprindo na medida em que oportunidades de engajamento na prática vão ocorrendo. A prática na comunidade gera, portanto, conhecimentos potenciais que podem ser aprendidos pelos estudantes que têm sua participação periférica legitimada.

De acordo com Wenger (1998), há quatro elementos que podem definir uma comunidade de prática: domínio, comunidade, prática e identidade, cada um com significado próprio. 0 domínio se refere aos assuntos sobre os quais os estudantes trocam informações, conhecimentos e partilha de saberes; a comunidade são as configurações sociais nas quais as práticas se definem como geradoras de participação e de reconhecimento; a identidade, constituída nas aprendizagens que transformam os sujeitos, dotando-os de histórias pessoais no contexto da comunidade; e a prática corresponde ao conjunto de saberes práticos que são partilhados.
Essas quatro vertentes são essenciais e estão presentes de modo equânime em uma comunidade de prática. Wenger (1998) alerta que a partir desses elementos é possível observar as fases de desenvolvimento e as principais preocupações associadas a cada fase, sendo que:

a) há a descoberta do potencial e a intenção principal da comunidade de prática quando ocorre a identificação da finalidade do domínio de interesse, da interação do grupo e da identificação das necessidades de conhecimentos comuns;

b) segue a agregação das partes, isto é, se estabelece o valor da partilha de conhecimento, se cria confiança suficiente para partilhar problemas e se estabelece conhecimento a partilhar e de como fazê-lo;

c) na maturação se estabelece o papel da comunidade de prática na organização/ sociedade a qual se mantém focada em sua finalidade, e a prática evolui da partilha para a organização e disponibilização de conhecimento;

d) na capitalização de conhecimento se mantém a relevância do domínio e se adquire estatuto para a comunidade de prática, estimulando a capacidade intelectual e mantendo-a à frente, ou seja, na vanguarda;

e) e, por fim, o momento da transformação, que pode levar à cisão, à extinção, ou a uma mudança significativa de domínio da comunidade de prática.

Com efeito, o foco principal da teoria de Wenger (1998, p. 4) é a "aprendizagem como participação social”. Essa aprendizagem não se refere somente a eventos locais de engajamento em certas atividades com certas pessoas, mas sim a um processo abrangente de sermos participantes ativos nas práticas de comunidades sociais e construirmos identidades em relação a essas comunidades.

Assim, o estudo com os estagiários, que está na base deste artigo, prioriza essas possibili- 
dades quanto à aprendizagem para a docência da educação básica. Tomando como referência os estudos de Reali (2009) e Mizukami (2010) sobre a formação docente, compreende-se a "aprendizagem docente" como ação contínua ao longo da carreira em que os professores aprendem ensinando e na relação com outros professores.

No que se refere aos conhecimentos a serem aprendidos, as discussões e definições na atualidade, expressas, por exemplo, na Resolução CNE no 2, de 1ํ de julho de 2015 (BRASIL, 2015), indicam que a formação docente nos cursos de licenciatura envolve: a) Conhecimentos sobre a Educação Básica e sua gestão; b) Compreensão do campo de conhecimento específico de sua especialidade, o que permite "mover-se no campo"; c) Domínio do conhecimento pedagógico do conteúdo a ser ensinado que fundamente ações didáticas pertinentes e diferentes para os diferentes conteúdos; d) Compreensão dos aspectos filosóficos, históricos, políticos e sociológicos da educação, integrando esses conhecimentos para a compreensão da realidade educacional de forma a orientar suas práticas profissionais; e) Compreensão do desenvolvimento e da aprendizagem de crianças e adolescentes em seus aspectos característicos sociais, psicológicos e culturais; f) Formação para o acompanhamento das ações educacionais e das progressões das crianças e adolescentes para realimentação pedagógica e gestão da escola, ou do sistema; g) Formação para o desenvolvimento de atitudes investigativas da prática educacional.

Também os estudos de Schulman $(1986)^{2}$ reforçam esses indicativos sobre a formação para a docência, no que concerne aos conhecimentos necessários para os professores, denominado por ele como Conhecimento do Conteúdo Pedagógico (Pedagogical Content Knowledge - P(K), os quais abrangem: a) conhecimento pedagógico geral, com especial referência aos

2 Sobre os conhecimentos necessários aos professores, há outros estudos realizados: Gatti e Barreto (2009), Romanowski (2016), Vaillant e Marcelo (2012), entre outros. princípios e estratégias de organização e gestão de sala de aula; b) conhecimento dos alunos e suas características; c) conhecimento dos contextos educacionais, que vão desde a relação entre grupos e em sala de aula, até a gestão e financiamento dos sistemas e instituições escolares, os conhecimento dos fins educativos, os efeitos e valores na perspectiva histórica e filosófica; d) conhecimento do conteúdo das disciplinas e atividades escolares; e) conhecimento do currículo, envolvendo compreensão dos materiais e programas que servem como "ferramentas de mediação" para professores; f) conhecimento do conteúdo pedagógico, que relaciona conteúdo e didática, "o que" e "como" ensinar , como conhecimento específico de professores. Esses conhecimentos são pertinentes à identidade docente quanto aos conhecimentos profissionais que se articulam à prática do professor.

Além dessas considerações sobre o ensino, Veiga (2015), ao propor examinar as questões que envolvem a docência quanto a possíveis encaminhamentos da didática, organizou o livro Lições de Didática. Nesse livro, escrito com a participação de professores pesquisadores da Didática, são evidenciadas as diferentes dimensões do ensino como prática social. Entre as dimensões registra-se a atividade e a intencionalidade de ensinar, a relação entre ensino e currículo, a interação entre professor e aluno, a pesquisa para e no ensino, a aprendizagem interativa e a avaliação da aprendizagem. Para essa autora, as referidas dimensões são componentes do ensinar e do aprender que caracterizam a ação docente. Ainda nessas considerações sobre a docência, Tardiff e Lessard (2005), ao indicarem os elementos da docência como um campo teórico, demarcam o trabalho docente como interativo, o qual envolve atuação nos processos de cognição de modo planejado. A esses autores se soma Hargreaves (1998), que examina as mudanças no trabalho do professor considerando a intensificação do trabalho diante das exigências da preparação da atividade docente, o individualismo e as 
formas de colaboração, considerando a reestruturação do ensino. Assim, para o estudo realizado com os estagiários em uma comunidade de prática, ao examinar os componentes da docência e da identidade do professor, esses autores constituem aportes fundamentais nas análises realizadas.

\section{Percurso metodológico}

A investigação de abordagem qualitativa, entendida como um processo contínuo de construção de versões da realidade fundamentada nas falas dos sujeitos da pesquisa sobre sua inserção em uma comunidade de prática, foi desenvolvida com três tipos principais de objetivos, quais sejam: os exploratórios, os descritivos e os explicativos (FLICK, 2008), tendo em vista examinar as possibilidades das comunidades de prática no processo de formação de professores de educação básica.

A coleta dos dados ocorreu durante um semestre letivo no qual, semanalmente, os estagiários e o pesquisador participaram de reuniões de comunidade de prática, que foi criada para atender ao propósito da pesquisa. 0 estudo desenvolveu-se na modalidade de pesquisa participante, que se traduz como um envolvimento legítimo entre o pesquisador, o objeto e os sujeitos de pesquisa. Segundo Brandão (1984, p. 12), a pesquisa participante "trata-se de um enfoque de investigação social por meio do qual se busca plena participação da comunidade na análise da própria realidade, com o objetivo de promover a participação social para o benefício dos participantes da investigação", o que parece adequado para o estudo realizado. A ideia de participação com a presença ativa do pesquisador e dos sujeitos pesquisados pode ser ao mesmo tempo um processo educativo, produzido dentro da ação. Isto é, no momento da inserção do pesquisador na comunidade de prática, como um espaço formativo, que possibilita a análise das experiências que geram a aprendizagem desses sujeitos envolvidos na Educação Básica.
A pesquisa foi realizada em uma instituição privada de Curitiba, Paraná, que apresenta uma relação diferenciada com o estagiário, a qual oportuniza o estágio não obrigatório, isto é, a instituição se preocupa com o trabalho desempenhado pelo estagiário, acompanha a sua formação docente no ambiente educacional da escola. Aliado a essa preocupação da escola com a formação dos estagiários, a comunidade de prática foi criada pelo interesse da investigação e com a aprovação da instituição como uma possibilidade de formação docente desenvolvida no ambiente escolar.

Trata-se de uma instituição confessional, de grande porte e referência de ensino na região de Curitiba, que atende alunos da educação infantil ao ensino médio, que visa ao cultivo de valores e cuja proposta pedagógica explora questões psicológicas, sociais, econômicas e culturais, plurais e complexas, permeada pelas novas tecnologias e pela pluralidade de linguagens. A escolha da instituição foi intencional, por acolher um número significativo de estagiários, favorecendo a constituição de uma comunidade de prática.

A pesquisa participante iniciou com entrevistas semiestruturadas e as conversas individuais com os coordenadores, os assessores, os professores regentes e a direção da instituição. Após vários contatos e argumentos sobre a possiblidade de realizar uma comunidade de prática na escola com os estagiários, com a autorização da direção, e o consentimento livre e esclarecido dos estudantes participantes do estudo, respeitando as normas éticas de pesquisa, foram iniciadas as reuniões com os estagiários. Cada encontro seguia um planejamento pré-definido, acertado com a participação dos estudantes. Participaram da comunidade de prática 17 estagiários dos cursos de Letras/Inglês, Letras/Espanhol, Matemática, Pedagogia, Educação Física e Ciências Biológicas.

As reuniões contavam com a participação das coordenações do ensino fundamental. ${ }^{3} \mathrm{~A}$

3 Neste artigo constarão apenas os depoimentos dos estudantes, não sendo incluídos os depoimentos dos coordenadores e dos professores. 
primeira reunião foi elaborada para explicar os objetivos do estudo, o interesse pelo grupo de estagiários e a relevância da pesquisa. Cada reunião seguia uma pauta construída com a participação dos estagiários, a partir de suas necessidades específicas durante o estágio não obrigatório.

As pautas das reuniões da comunidade de prática refletiam as demandas do processo da formação docente desses estagiários, possibilitando a compreensão da formação docente, as concepções e práticas desenvolvidas no estágio não obrigatório. Durante as reuniões de comunidade de prática e as entrevistas individuais, as falas foram gravadas em fitas $\mathrm{K} 7 \mathrm{e}$ transcritas a seguir. Para refinar as transcrições foram necessários vários contatos com cada estagiário por meio de um grupo no WhatsApp e por e-mails, que possibilitaram a troca de informações e o acompanhamento da formação docente realizada.

De acordo com Szymanski, Almeida e Prandini (2008), a entrevista representa uma situação de interação humana em que estão em jogo percepções, expectativas, sentimentos e interpretações entre o entrevistador e o entrevistado. Pela entrevista tem-se a possibilidade de analisar os significados subjetivos, bem como temas complicados de serem analisados de forma padronizada. Assim que as entrevistas semiestruturadas foram respondidas pelos estagiários, os dados foram organizados e categorizados para possibilitar a análise. As questões foram, em sua maioria, abertas e com possibilidade de manter mais de um contato com o entrevistado com a finalidade de ser fiel na compreensão e entendimento sobre a situação relatada, possibilitando uma análise mais apurada e sistemática. No primeiro momento, o Excel foi empregado para registrar as respostas; para categorizá-las utilizou-se o software NVIVO9, e assim foi possível organizar um banco de dados.

Com o crescente interesse em valorizar as falas e manifestações dos sujeitos no decorrer das análises do objeto de estudo, foi possível criar identidade com a análise de conteúdo definida por Bardin (2010, p. 7, grifo do autor) como "um conjunto de instrumentos metodológicos cada vez mais sutis em constante aperfeiçoamento, que se aplicam a 'discursos' (conteúdos e continentes) extremamente diversificados".

Nessa perspectiva, todo o material coletado - entrevistas semiestruturadas, falas dos participantes da comunidade de prática e registros do grupo no WhatsApp - foi organizado. De acordo com Bardin (2110, p. 121), a análise de conteúdo organiza-se em três fases: 1 . A pré-análise; 2. A exploração do material; e, por fim, 3. 0 tratamento dos resultados: a inferência e a interpretação. Assim sendo, na fase da pré-análise foi preciso a retomada do objeto e dos objetivos da pesquisa, escolha inicial de indicadores para a análise, como definição de unidades de registro, palavras-chave ou frases e unidades de contexto, que encaminharam e focaram à próxima etapa de pesquisa. Nessa fase a leitura flutuante foi necessária para organizar e captar o conteúdo, considerando normas de validação para constituir o corpus de análise, tendo em vista alcançar o universo pretendido, promover homogeneidade entre a coerência interna de temas, técnicas e interlocutores, assumindo a adequação ao objeto e ao objetivo do estudo.

Uma segunda fase, de exploração do material, diz respeito à realização propriamente dita das definições anteriores, para sistematizar e organizar os dados coletados, resultando na delimitação das categorias de análise. Nessa fase aconteceu a referenciação dos índices e a elaboração de indicadores, recortes do texto e categorização, isto é, o aprofundamento das reflexões da pesquisa com os estagiários. Portanto, foram realizados o entrecruzamento e a análise dos dados coletados, resultando no apontamento das contribuições para a formação docente do estagiário durante a realização do estágio não obrigatório em comunidade de prática.

A participação dos estagiários nas reuniões de comunidade de prática ocorreu de 
maneiras diferenciadas: a partir de temas específicos; apresentando situações de seu dia a dia; apresentando soluções para situações de seus colegas de estágio; contando o que aprendeu; socializando casos de alunos que precisam de ajuda coletiva; compartilhando suas dúvidas conceituais; solicitando estratégias de ensino que podem favorecer a aprendizagem dos alunos; apresentando estratégias bem-sucedidas e que promoveram aprendizagem coletiva ou individual do grupo de alunos que acompanham; apresentando registros de alunos que aprenderam a partir das mediações; apresentando as dificuldades para conduzir os grupos de alunos em sala de aula, entre outros.

O estágio não obrigatório, ${ }^{4}$ na atualidade, está regulamentado pela Lei no 11.788 , aprovada pelo Congresso Nacional e sancionada em 25 de setembro de 2008 (BRASIL, 2008). A legislação determina que o Projeto Pedagógico dos Cursos indique como se realiza o estágio não obrigatório. No entanto, as Diretrizes Curriculares de formação de professores não incluem o estágio não obrigatório. Isso gera dubiedade no processo de formação, pois o estágio supervisionado é componente dos projetos de curso indicado nas diretrizes, mas o estágio não obrigatório fica à margem das propostas de curso. Ressalta-se que o estágio não obrigatório pode ingressar o estudante no mercado de trabalho, sendo uma atividade opcional dada ao aluno interessado que vem acrescer à carga horária regular e obrigatória, conforme a Lei do Estágio. Entretanto, muitas vezes, o estágio não obrigatório é realizado como mão de obra barata, o estagiário passa a ser um trabalhador comum, não é considerado um estudante em formação, a finalidade do estágio é deturpada (GONÇALVES, 2007).

Muitas licenciaturas brasileiras não registram o estágio não obrigatório como estágio, o que é um direito do estudante estabelecido no

4 Sobre o estágio não obrigatório, consultar Prates (2016), que detalha e discute com maior aprofundamento a questão, não examinado neste artigo dado os limites do texto. parágrafo $2 .^{\circ}$ do art. 2.ำ da Lei n⿳0 11.788/2008, sendo a carga horária do estágio curricular não obrigatório "acrescida à carga horária regular e obrigatória” (BRASIL, 2008). Portanto, é necessário que a matriz curricular preveja esse componente e que o regulamento do estágio estabeleça normas para sua eleição, autorização, supervisão e validação de créditos.

\section{As aprendizagens da docência em comunidade de prática: indicações a partir dos estudantes}

Os dados coletados por meio do registro das reuniões e das entrevistas com os estagiários participantes da comunidade de prática, após sua organização e sistematização, tendo em vista examinar as possibilidades das comunidades de prática no processo de formação de professores para a educação básica, possibilitaram uma análise densa, articulada aos referenciais que constituem os aportes do estudo. Dessa análise foi possível levantar os seguintes indicadores: a) a organização da comunidade de prática e sua articulação com os pressupostos em Wenger; b) a participação na comunidade e as aprendizagens da docência; c) a formação para a docência nas interações realizadas entre os estudantes; d) as reflexões na comunidade de prática e a constituição da identidade docente.

\section{A organização da comunidade de prática e sua articulação com os pressupostos em Wenger}

Durante o semestre de realização das reuniões com os estagiários depreendeu-se a formação da comunidade de prática e suas implicações no grupo de estagiários da instituição pesquisada, como se apresenta no Quadro 
1. Os pressupostos de Wenger (1998) foram sistematizados na coluna 1 e as expressões manifestadas durante as reuniões estão relacionadas na coluna 2 .

Quadro 1 - Indicadores de Wenger (1998) da formação da comunidade de prática e os resultados obtidos na investigação

\begin{tabular}{|c|c|}
\hline $\begin{array}{c}\text { INDICADORES DA FORMAÇÃO DE UMA COMUNIDADE } \\
\text { DE PRÁTICA PROPOSTA POR WENGER }\end{array}$ & $\begin{array}{l}\text { INDICADORES OBSERVADOS NO GRUPO DE } \\
\text { ESTAGIÁRIOS (ESTÁGIO NÃO OBRIGATÓRIO) }\end{array}$ \\
\hline $\begin{array}{l}\text { Relação mútuas sustentadas, sejam elas } \\
\text { harmoniosas ou conflituosas. }\end{array}$ & $\begin{array}{l}\text { Se engajavam no grupo, demostrando } \\
\text { respeito a diferentes opiniões. }\end{array}$ \\
\hline $\begin{array}{l}\text { Maneiras compartilhadas de engajamento } \\
\text { para fazer as coisas juntos. }\end{array}$ & $\begin{array}{l}\text { Todos se engajavam em ajudar os colegas } \\
\text { na produção dos planos de aula e na } \\
\text { aplicação das aulas na escola. }\end{array}$ \\
\hline $\begin{array}{l}\text { Rápido fluxo de informaç̃ões e } \\
\text { propagação de inovações. }\end{array}$ & $\begin{array}{l}\text { Compartilhavam informações durante as } \\
\text { reuniões e também fora delas, por e-mails e } \\
\text { redes sociais (WhatsApp). }\end{array}$ \\
\hline $\begin{array}{l}\text { Ausência de comentários introdutórios, } \\
\text { como se as conversas e as interações fossem } \\
\text { continuação de um processo em curso. }\end{array}$ & $\begin{array}{l}\text { A interação era facilitada pela } \\
\text { amizade e confiança que se formou ao } \\
\text { longo das reuniões. }\end{array}$ \\
\hline $\begin{array}{l}\text { Rápida exposição de um problema } \\
\text { a ser discutido. }\end{array}$ & $\begin{array}{l}\text { Expunham suas dificuldades durante as } \\
\text { reuniões de discussão, onde todos se } \\
\text { engajavam para ajudar. }\end{array}$ \\
\hline $\begin{array}{l}\text { Coincidência substancial nas descrições dos } \\
\text { participantes que pertencem à comunidade. }\end{array}$ & $\begin{array}{l}\text { O convívio e o engajamento permitiram } \\
\text { a formação de algumas características em } \\
\text { comum. Todos tinham grande interesse pela } \\
\text { docência e falaram disso frequentemente. }\end{array}$ \\
\hline $\begin{array}{l}\text { Saber o que os outros sabem, o que } \\
\text { podem fazer, e como podem contribuir } \\
\text { para o empreendimento. }\end{array}$ & $\begin{array}{l}\text { Conheciam as habilidades de seus colegas, } \\
\text { mesmo os membros mais novos se tornavam } \\
\text { conhecidos ao longo do tempo. Cada um era } \\
\text { solicitado a ajudar de forma a contribuir com a } \\
\text { prática em sala de aula. }\end{array}$ \\
\hline Identidades definidas mutuamente. & $\begin{array}{l}\text { Todos se identificavam como membros } \\
\text { do grupo e em formação. }\end{array}$ \\
\hline
\end{tabular}

Fonte: Prates (2016, p. 100).

A comunidade de prática favorece aprendizagens gerais de interação entre seus membros, pois se trata de um trabalho em grupo, uma vez que a comunidade se forma pela prática de trabalho produzida em conjunto. Uma das caraterísticas desse grupo foi o estabelecimento de interações por compartilhar informações durante as reuniões e também fora delas, por e-mails e redes sociais (WhatsApp), como ex- pressou o Estagiário B durante as entrevistas: "Acho que o que todo mundo compartilhava como principal é o sentido de desenvolver os conteúdos de forma que o aluno chegasse ao conceito, sem você precisar ficar passando as informações automaticamente." (PRATES, 2016, p. 97).

Ao envolver sujeitos diferentes para atuarem em conjunto considerando objetivos comuns, há 
exigência constante de negociação. Ao final, na avaliação das atividades realizadas, o Estagiário $G$ destaca que aprendeu a trabalhar em grupo.

Eu aprendi a trabalhar em grupo [...] é legal você ouvir críticas quando você faz alguma coisa porque te ensina, né, como você pode fazer de uma melhor forma. Então eu achei que as discussões das reuniões eram fundamentais, porque principalmente quando você não tem experiência e você elabora uma aula em casa, sozinha, você não tem muita dimensão de como que os alunos vão atender aquilo e quem já tem mais experiência já sabe, né. (PRATES, 2016, p. 98).

Os estagiários enfrentaram, no início das reuniões da comunidade de prática, dificuldades de trabalhar em duplas, trios com pessoas de opiniões diferentes e de outras áreas de formação, e também de ouvir a opinião sobre o plano de aula que haviam elaborado. No entanto, não deixaram de manifestar suas opiniões. As falas a seguir dos Estagiários $\mathrm{M}$ e $\mathrm{N}$, respectivamente, exemplificam esta situação:

Eu aprendi a respeitar a opinião alheia, mas também a manter a minha opinião de acordo com argumentos lógicos. Claro que você saber recuar numa proposta, num planejamento. É importante porque significa que você percebeu a perspectiva do outro. Por isso que a gente compartilha e conversa sobre a intervenção, e o grupo pode contribuir. (PRATES, 2016, p. 99).

Eu aprendi a conviver com pessoas que pensam de forma diferente da minha. (PRATES, 2016, p. 99).

Essas falas também permitem inferir a interação entre os estagiários facilitada por estarem no mesmo espaço e na mesma condição. No decorrer das reuniões, a amizade e a confiança entre os estudantes foram ampliadas, como afirma o Estagiário A:

Eu acho que foi legal. Pelo menos no meu grupo, com quem eu trabalhei, eu achei que todos estavam bastante engajados. Tanto que essa questão de a galera ir assistir às intervenções alheias [...]. Eu tive duas intervenções muito interessantes que os outros colegas de estágio vieram ajudar e eu achei que isso que aconteceu foi muito legal. Pelo menos nessa questão esse grupo foi divertido. (PRATES, 2016, p. 93).
Wenger (1998) afirma que a aprendizagem desenvolvida em comunidades de prática promove o engajamento mútuo no processo de envolvimento para desenvolver uma relação mútua e no conhecimento do outro. Concomitantemente, amplia o relacionamento e entendimentos e favorece a afinação ao projeto. E, por fim, a aprendizagem está relacionada ao desenvolvimento de repertórios, de estilos e de discursos, renegociando o significado de alguns elementos, produzindo e adotando certas ferramentas, artefatos, recordando eventos, adotando novas terminologias e abandonando outras.

Com efeito, no grupo de estagiários o engajamento na comunidade, a preocupação com as atividades e o compartilhamento de repertórios resultaram em aprendizagem, como sistematizado a seguir.

a) envolvendo formas de engajamento mútuo - o engajamento entre os estagiários resultou em aprendizagem pela troca de experiências, uma vez que todos tinham a liberdade de sugerir alterações nos planos de aula, sugerir métodos a serem utilizados em aula, ou mesmo discutir algum conceito específico de sua área de formação acadêmica.

b) entendendo o projeto - o entendimento do projeto se deu pela vivência e pela experiência, o que resultou em aprendizagem. A preocupação com o desenvolvimento das atividades também fez com que os estagiários desenvolvessem conhecimentos compartilhados sobre o ensino, o que resultou na aprendizagem sobre a produção de planos de aula e a atuação em sala de aula.

c) desenvolvendo o repertório do grupo - a troca de experiências, de sugestões e de ideias que eram dadas para a produção dos planos de aula, o compartilhamento das formas de fazer e também do conhecimento teórico que os estagiários tinham resultaram na aprendizagem de todos tanto na perspectiva de um 
repertório para a prática, como sobre as teorias de ensino.

\section{A participação na comunidade e as aprendizagens da docência}

Entre as aprendizagens da docência vivenciadas na comunidade de prática, as questões relativas ao ensino foram destacadas: a identificação da abordagem de ensino, a organização do planejamento, o modo de comunicar os conteúdos, situações relativas às metodologias de ensino. Os estagiários, em geral, relataram terem aprendido mais sobre a prática em sala de aula, novas formas de ensinar, novas ferramentas a serem utilizadas no ensino dos conteúdos e também a trabalhar em grupo, relacionar-se com pessoas de opiniões diferentes. Essas aprendizagens são reconhecidas como conhecimentos docentes. A este respeito, Schulman (1986) indica que a prática docente é um dos componentes do Conteúdo Pedagógico. Veiga (2015) aponta que a prática abrange a organização do processo ensino e aprendizagem. A fala do Estagiário C expressa essas aprendizagens, como busca de ensinar sem se valer de aulas expositivas:

Aprendi a ensinar sem agir de forma muito expositiva. Quando vocês falavam que a nossa primeira intervenção estava expositiva demais, para a gente procurar mudar, eu vi que vocês bateram nessa tecla mais de uma vez, mas para mim, quando eu ouvia isso, não surtia muito efeito, eu achava: 'Ah, eles estão dizendo que está muito expositiva, mas na hora eu vou tentar fazer uma coisa diferente e não vai ficar.' (PRATES, 2016, p. 98).

No depoimento do Estagiário E, a percepção da importância no modo de comunicar os conteúdos:

Eu acho que a coisa mais importante que eu aprendi foi explicar um conteúdo em sala de aula. Eu lembro que a primeira vez que eu entrei numa sala, um aluno não conseguia entender do jeito que eu falava, eu me desesperei e quis sair chorando, foi a inexperiência. Com o estágio, eu aprendi a me planejar, a pensar o próximo passo e a falar já tipo: 'está bom se ele não entendeu direito, vamos pensar de uma outra maneira.' (PRATES, 2016, p. 98).

E nas falas dos Estagiários N, E e G, respectivamente, a organização das aulas de modo sistematizado e com uso de recursos didáticos, e o planejamento do ensino antecipadamente, considerando a metodologia e a diversificação:

Eu aprendi mais sobre sequências didáticas. Também gostei que a gente teve oportunidade de usar outros tipos de coisas; a gente usou o lego, as meninas fizeram modelos com a massinha. Eu nunca tinha pensado em fazer isso e achei bem legal porque é simples, né.

$\mathrm{Eu}$ acho que a coisa mais importante que eu aprendi foi a explicar um conteúdo em sala de aula. Eu lembro que a primeira vez que eu entrei numa sala, um aluno não conseguia entender do jeito que eu falava, eu me desesperei e quis sair chorando, foi a inexperiência. Com o estágio, eu aprendi a me planejar, a pensar o próximo passo e a falar já tipo: 'está bom se ele não entendeu direito, vamos pensar de uma outra maneira.'

Então eu achei que as discussões das reuniões eram fundamentais, porque principalmente quando você não tem experiência e você elabora uma aula em casa, sozinha, você não tem muita dimensão de como os alunos vão atender aquilo e quem já tem mais experiência já sabe, né. (PRATES, 2016, p. 98).

Nos momentos de discussão e de aplicação dos planos de aula, os estagiários se mostraram envolvidos no projeto construído coletivamente e colaboraram com os outros. Essa interação não foi demonstrada apenas com os colegas que participaram de alguma forma do plano de aula, mas uma preocupação entre todos os estagiários envolvidos. Os trechos a seguir, coletados dos registros de reunião da comunidade de prática (PRATES, 2016, p. 186-187), exemplificam essa interação, considerando uma situação didática em que os estagiários $B, D$ e F se envolveram.

[...] então eu pensei em fazer alguma coisa relacionada à alimentação. Dar algum texto mais tranquilo, e eu achei esse caderno temático aqui que tem vários textos legais, dá para tirar trechos. Aqui tá usando uma nomenclatura bem 
simples e acessível ao ano que pretendo aplicar. Pensei em dar um texto pra eles lerem sobre a alimentação saudável e depois ir perguntando, questionando o que eles entenderam do texto e deixar eles construírem conceitualmente as informações, relacionar as informações que tem aqui no texto [...]. (ESTAGIÁRIO B).

Eu acho que alimentação é um pouco ainda meio [...] sei lá, pela forma como você for colocar talvez possa ter muitos nomes complicados ou muita coisa visual que talvez eles não estejam tão adaptados, é um tanto pesado ainda. É opinião particular, eu acho que pode ser muito interessante pra uma turma de Ensino Fundamental II [...]. (ESTAGIÁRIO D).

É, eu dei uma lida aqui e está bem para Ensino Médio mesmo, né, até superior. (ESTAGIÁRIO B).

Até porque isso exige uma curiosidade que a gente tem mais quando a gente conhece a química orgânica, tipo começar a ler rótulo de embalagem [...]. (ESTAGIÁRIO F).

Então, eu acho legal, mas eu tenho muito medo de trabalhar de uma forma muito complexa e os alunos não entenderem nada, por exemplo, não conseguirem fazer muitas relações com o que eles já viram [...]. (ESTAGIÁRIO B).

É, eu estou tentando ver sobre o fechamento, não sei se precisa fazer um fechamento geral de tudo. Talvez a ideia de pegar um texto bem lúdico e conceitual assim, na área da saúde, para fazer um fechamento até que seria legal também. Mas a ideia é introduzir algo novo também [...] uma revisão final. (ESTAGIÁRIO F).

Não chega a ser uma revisão final, mas a questão é que você poderia introduzir conceitos novos, mas de uma forma que você utilize como ferramenta o que foi capturado durante todo o processo, entendeu? (ESTAGIÁRIO D).

Os depoimentos permitem inferir que as aprendizagens envolveram situações relativas à prática docente, desde o planejamento de ensino até a preocupação com os procedimentos didáticos, ainda que de modo fragmentado e não sequencial. Dependia das situações e questões propostas pelos estagiários. A comunidade não é o desenvolvimento de um curso ou programa sistemático de formação. As situações discutidas e examinadas pelos participantes são originadas na prática, ou seja, em cada reunião os estagiários estabelecem uma pauta de assuntos a serem examinados considerando os fatos observados e registrados durante a semana na sala de aula em que desenvolviam suas atividades de estágio. Os estagiários atuam como auxiliares e apoio dos professores regentes das turmas nas salas de aula, nas atividades de apoio ao estudo dos alunos que realizam período de aulas em tempo integral, no acompanhamento de estudos individuais dos alunos e no apoio nos horários de refeições dos alunos. Destas atividades realizadas é que foram pautados os assuntos discutidos na comunidade. A comunidade de prática assumiu ser um espaço de discussão e exame das observações dos estagiários, e como as atividades realizadas eram relativas ao ensino, as aprendizagens mantiveram este foco em torno da docência.

\section{A formação para a docência nas interações realizadas entre os estudantes}

No desenvolvimento da comunidade de prática os estagiários se reportaram a aprendizagens que remetem ao processo de formação docente. Entre elas foram destacadas a relação entre a teoria e prática. Para eles, as disciplinas dos cursos de licenciatura privilegiam a teoria e abordam pouco a prática docente como a metodologia de ensino expressa nas formas de ensinar e analisar os resultados das aulas. Nas reuniões de comunidade de prática, esses estagiários buscaram estabelecer relação entre teoria e prática, contribuindo com a sua formação nos cursos de licenciatura, como mostra a fala do Estagiário $\mathrm{G}$ a seguir:

Na verdade, as reuniões me ensinaram a criticar um pouco as metodologias da licenciatura. Eu já fiz algumas matérias da licenciatura e eu vi que as reuniões agregam bastante para mim como é a função de professor. A licenciatura me deixa um pouco chateada com essa discussão só sobre a teoria [...] eu não acho que não seja importante discutir teorias, mas eu acho importante discutir 
as metodologias também. Então, me fez olhar com um olhar um pouco mais crítico, pensando que, às vezes, um bom professor não tem que enfatizar só a parte prática e também não só a teórica. Eu acho que ele tem que juntar essas duas partes e isso me fez olhar a licenciatura de uma nova forma, assim, como eu posso pegar aquela teoria discutida e colocar em prática. (PRATES, 2016, p. 107).

A compreensão de conhecimentos abordados no curso assumiu uma perspectiva de inserção para a prática docente. Uma prática fundamentada, contribuindo com a formação profissional dos estagiários, como, por exemplo, um depoimento do Estagiário L que expressa que os conhecimentos estudados no curso adquiriram relação com a docência para além de conceitos:

[...] quando um professor fazia alguma observação sobre a aprendizagem dos alunos ou como os alunos aprendem, eu começava a me enxergar falando alguma coisa e lembrando de alguma experiência que eu tive de um aluno respondendo uma coisa certa ou errada, aprendendo ou errando comigo. Então, eu acho que isso [a experiência da comunidade de prática] pode ter me ajudado. (PRATES, 2016, p. 106).

Além disso, se evidencia que a participação na comunidade de prática agregou novos conhecimentos, ampliando a formação. Tardif e Lessard (2005) ressaltam que as práticas vivenciadas designam um saber-fazer, entendido como um conhecimento trabalhado. Que esse conhecimento prático advindo por meio da experiência não se torna um discurso teórico, mas assume uma perspectiva epistemológica, por possuir características das ciências humanas e sociais.

0 depoimento abaixo reafirma que a formação do professor se articula à experiência, isto é, as experiências vivenciadas no estágio contribuem para a formação docente. Não se trata de negar os conhecimentos aprendidos nos cursos, mas de considerar os conhecimentos aprendidos na experiência. As aprendizagens realizadas na comunidade de prática podem considerar as possibilidades de uma produção e sistematização coletivas de conhecimentos, em que a teoria produzida durante os debates, as discussões e as reflexões são a expressão da prática vivenciada por eles, como propõe Martins (2016). Afirma essa autora que o eixo epistemológico de um processo de reflexão da prática constitui "a concepção da teoria como expressão de uma determinada prática e não de qualquer prática" (MARTINS, 2016, p. 20). Nas palavras do Estagiário $\mathrm{H}$ : “[...] às vezes, o que é passado em sala de aula na faculdade não é o suficiente para atuarmos na prática. Na prática ganhamos muita experiência e aprendizado, que é significativo para a formação profissional." (PRATES, 2016, p. 109).

Ainda em relação à formação com a participação em comunidade de prática, evidencia-se uma aprendizagem de escolhas a serem feitas pelo professor em situação, considerando os eventos em cada classe, que de modo geral são únicos e originais (TARDIF; LESSARD, 2005). No processo de formação esse é um dos conhecimentos fundamentais, pois na realização das aulas o professor precisa tomar decisões para desenvolver o ensino. 0 depoimento do Estagiário J confirma esta aprendizagem: "Outra coisa que apenas a escola ensina são as posturas que você deve ter, como agir nas mais diversas situações, que estratégias você pode adotar." (PRATES, 2016, p. 109).

A comunidade de prática oportunizou a aprendizagem da profissão como compromisso coletivo em que a colaboração e o compartilhamento são enfatizados como necessários pelos próprios professores, como explica Veiga (2015, p. 22): "ensinar implica interações concretas entre pessoas", pois o ensino é uma atividade de interações. Nessa perspectiva, o depoimento do Estagiário $\mathrm{N}$ expressa o compromisso com esse processo de interação: “[...] sendo a honestidade e a cooperação aspectos fundamentais. Assim, sendo críticos e honestos conosco e com os nossos colegas, a nossa formação será ainda maior e o nosso crescimento como futuros professores também." (PRATES, 2016, p. 114) 
A formação de professores é um processo contínuo, pois pode ser entendido como iniciado durante a escolarização, ainda que de modo precário. Especificamente, se constitui durante a formação profissional nos cursos normal em nível médio e licenciaturas. Estes cursos são a base da formação para a profissão. Os primeiros anos de atuação profissional possibilitam a compreensão da prática com intenso aprendizado da docência. A formação continuada se integra a esse processo ao longo do exercício profissional para atualização, aperfeiçoamento, aprofundamento da atuação profissional em que o professor de aprendente se torna experiente e, por fim, referência para os demais professores. Esse processo pode ser entendido como desenvolvimento profissional docente abrangendo antecedentes, formação básica e formação continuada. Os elementos que constituem este processo envolvem conhecimentos pedagógicos, conhecimentos específicos, conhecimentos sociopolíticos, teóricos e práticos amalgamados no ser professor. Portanto, a formação é uma construção constante, efetivada pela reflexão, provocando avaliações e mudanças realizadas por rupturas e continuidades. Não se trata de um processo linear, mas contraditório, em permanente revisão para recompor e mesmo desistir. Esse processo se efetiva por autoformação, heteroformação e formação coletiva. Assim, a formação realizada durante a comunidade de prática mostrou-se uma contribuição nesse processo ao envolver os estagiários em situações de prática profissional, discussões de conceitos e conhecimentos da docência e nos processos de cooperação para planejamento e sugestões de possibilidades de atuação na escola.

\section{As reflexões na comunidade de prática e a constituição da identidade docente}

Os relatos dos estagiários também mostram que se identificaram como professores em for- mação no contexto da comunidade de prática. Todos são estudantes de cursos de licenciatura. A identificação como professores em formação ocorreu com a prática das atividades durante o estágio não obrigatório, o qual envolveu construção coletiva de planos de aula, situações de sala de aula, organização de atividades pedagógicas, investigação de possibilidades de contribuir com a aprendizagem dos alunos, principalmente dos que apresentavam dificuldades em aprender determinados conteúdos trabalhados em aulas. Segundo Wenger (1998), a experiência de identidade na prática é uma forma de pertença ao contexto em que os sujeitos se encontram. 0 depoimento do Estagiário L é um exemplo de que a identidade docente foi possibilitada nas reflexões e interações:

A experiência como estagiária tem me ajudado muito, pois estou tendo a oportunidade de trabalhar na área educacional e isso tem me agradado muito. É maravilhoso trabalhar aqui, diria que a experiência como estagiária não está ajudando apenas na minha formação, mas me ajuda como pessoa. Isto é muito significativo. (PRATES, 2016, p. 109).

Essa possibilidade, ao mesmo tempo que gerou uma identificação com a profissão, também produziu insegurança, como diz o Estagiário $\mathrm{N}$ : "[...] confesso que inicialmente foi dura a sensação de ser identificado como professor e de sentir a responsabilidade que me estava a ser passada, responsabilidade essa que a meu ver se tornou o começo da construção do meu percurso como estagiário." (PRATES, 2016, p. 114).

Destarte, no enfrentamento dessas inseguranças as interações foram fundamentais. De simples troca de informações e experiências, as relações estabelecidas foram ampliadas e a participação assumiu autenticidade reconhecida como importante para o desenvolvimento da identidade docente, como vemos no depoimento do Estagiário N: "[...] sendo a honestidade e a cooperação aspectos fundamentais. Assim, sendo críticos e honestos conosco e com os nossos colegas, a nossa formação será ainda 
maior e o nosso crescimento como futuros professores também." (PRATES, 2016, p. 114).

Também em torno da insegurança foi detectado nos registros que as interações adquiriram potencialidade no desenvolvimento da segurança de tornar-se professor, como aponta o Estagiário 0: "antes, focávamos nos pontos negativos, [...] para melhorarmos. Agora temos mais a noção daquilo que fazemos bem." (PRATES, 2016, p. 115).

Os estagiários foram unânimes em considerar que querem assumir a ajuda a seus alunos e possibilitar práticas consistentes. A propósito, afirma o Estagiário H: "quero ser alguém que marca os alunos positivamente, pelas boas práticas." (PRATES, 2016, p. 116). Esse propósito de se tornar professor e promover boas práticas está também presente no término das reuniões da comunidade; e como alguns estavam finalizando o seu estágio não obrigatório na instituição, então tinham esse posicionamento, a exemplo do Estagiário $\mathrm{F}$.

Lembro-me no início do estágio que falei que queria ter uma boa relação com os meus alunos [...] e conseguir ter uma influência positiva na sua vida e na sua formação. E acho que, sinceramente, esse é um dos objetivos que tanto eu como os meus colegas estamos conseguindo atingir. (PRATES, 2016, p. 116).

Ser professor foi a profissão que elegeram e objetivam tornar-se bons professores. Para alcançarem esse propósito, os estagiários reconhecem a necessidade de desenvolver práticas reflexivas de interação, como se pode observar por meio do comentário do Estagiário D:

As reflexões formais [...] têm uma expressão crítica relativamente à nossa atuação e permitem-nos [...] reformular ou reforçar a nossa atividade para um próximo momento que apresente características idênticas àquele sobre $o$ qual refletimos. [...] Aqui incluo as reflexões em conjunto após as aulas, o turbilhão de ideias que ocorrem ao longo do ano com o objetivo de analisar a nossa intervenção nos diferentes momentos. Considero estes momentos de partilha e discussão como os mais ricos em aprendizagem ao longo deste ano de estágio, uma vez que nos proporcionaram uma enorme variedade de contextos e situações para refletir e analisar. (PRATES, 2016, p. 116).

Desse modo, os registros confirmam as contribuições das interações na construção de identificação com a profissão, como afirma Hargreaves (1998, p. 266): "pertencer a uma comunidade, partilhar crenças e finalidades educativas, trabalhar em conjunto, relacionarse bem com os membros do grupo" aprimora a identidade da escola e também dos professores. Nessa pesquisa, a participação em uma comunidade de prática indica uma forte possibilidade de oferecer situações para a que os estagiários superem a condição de isolamento e de individualização na realização de suas atividades. Os depoimentos apontam para intensificação das aprendizagens de tornar-se professor.

\section{Considerações finais}

O estudo realizado com estagiários que participaram de uma comunidade de prática em uma escola da educação básica permitiu examinar as possibilidades que esta participação proporciona quanto à aprendizagem da docência.

Ao sistematizar e constituir a comunidade de prática com os estagiários, os cuidados e critérios propostos pela Teoria Social de Aprendizagem foram tomados no encaminhamento das reuniões e participações. A avaliação realizada permitiu indicar que esse grupo desenvolveu uma comunidade de prática permitindo aprendizagens por favorecer o engajamento, $o$ compartilhamento de experiências e conhecimentos, a convivência e a interação, bem como a identificação com os grupos.

Em relação à comunidade de prática, durante a investigação foi possível verificar que este processo de formação é pouco presente na formação realizada com estudantes de licenciatura. Foram localizados apenas quatro artigos (CUNHA, 2013; SILVA; MARIALVA, 2016; MENEZES, 2014; NAGY; CYRINO, 2014) sobre o assunto na base Educ@, da Fundação Carlos 
Chagas (FCC). Nessa perspectiva, é sugestão realizar um estudo de revisão sistemática sobre a formação de professores em comunidades de prática.

Na perspectiva de resultados da investigação realizada, a análise dos dados indica que essa composição de participação e interação entre estudantes de cursos de licenciatura favorece alargar a formação e a aprendizagem da docência e mesmo a constituição da identidade docente. As aprendizagens em torno da organização do ensino, da promoção da aprendizagem dos alunos, da identificação de dificuldades de aprendizagem de determinados conhecimentos pelos alunos, da elaboração de planejamento das situações de ensino, de busca de procedimentos e de recursos didáticos foram destacadas. Também foi alvo de distinção as interações entre os estagiários como forma de melhorar a atuação docente.

De outra perspectiva, foi constatado que o estágio não obrigatório pode constituir-se em processo de formação dos professores se devidamente programado para proporcionar reflexões, discussões e trocas entre os estagiários. É urgente considerar este estágio para além dos acompanhamentos formais e burocráticos. 0 acompanhamento pelos envolvidos, estabelecendo uma interação entre a escola, os cursos e os estagiários, poderá contribuir para superação do estágio apenas como atuação do estagiário em atividades de apoio. Em outros termos, esse estágio pode ser efetivamente um espaço de formação para além da balcanização e atuação individual do estagiário. É potencialmente um campo de formação para a docência.

Por fim, o estudo indica a necessidade de novas pesquisas com comunidades de prática para que se explicite melhor suas possibilidades de formação e aprendizagem da docência para a educação básica.

\section{REFERÊNCIAS}

ANDRE, M. E. D. A.; ROMANOWSKI, J. P. O tema formação de professores nas dissertações e teses.
In: MARLI, E. D. A.; ANDRÉ, M. E. D. A. (org.). Formação de professores no Brasil (1990-1998). 2. ed. Brasília, DF: INEP, 2002. p. 17-155.

BARDIN, L. Análise de conteúdo. 5. ed. Lisboa: Edições 70, 2010.

BRANDÃO, Carlos R. (org.). Pesquisa participante. São Paulo: Brasiliense, 1984.

BRASIL. Presidência da República. Casa Civil. Lei no 11.788, de 25 de setembro de 2008. Dispõe sobre o estágio de estudantes; altera a redação do art. 428 da Consolidação das Leis do Trabalho - CLT, aprovada pelo Decreto-Lei ${ }^{\circ} 5.452$, de $1^{\circ}$ de maio de 1943, e a Lei n ${ }^{\circ}$ 9.394, de 20 de dezembro de 1996; revoga as Leis $\mathrm{n}^{\circ \mathrm{s}} 6.494$, de 7 de dezembro de 1977 , e 8.859, de 23 de março de 1994, o parágrafo único do art. 82 da Lei $\mathrm{n}^{\circ}$ 9.394, de 20 de dezembro de 1996, e o art. $6^{\circ}$ da Medida Provisória n 2.164-41, de 24 de agosto de 2001; e dá outras providências. Brasília, DF, 2008. Disponível em: http://www. planalto.gov.br/ccivil_03/_ato2007-2010/2008/ lei/l11788.htm. Acesso em: 18 nov. 2019.

BRASIL. Ministério da Educação. Conselho Nacional de Educação. Conselho Pleno. Resolução CNE/ CP no 02, de 01 de julho de 2015. Define as Diretrizes Curriculares Nacionais para a formação inicial em nível superior (cursos de licenciatura, cursos de formação pedagógica para graduados e cursos de segunda licenciatura) e para a formação continuada. Brasília, DF, 2015. Disponível em: http://portal.mec.gov.br/docman/agosto-2017pdf/70431-res-cne-cp-002-03072015-pdf/file. Acesso em: 18 nov. 2019.

BRZEZINSKI, I. Formação de profissionais da educação (2003-2010). Vol. 1. Brasília, DF: INEP, 2014.

BRZEZINSKI, I.; GARRIDO, E. (org.) Formação de profissionais da educação. Série Estado do Conhecimento (1997-2002). 10. ed. Brasília, DF: Instituo Anísio Teixeira, 2006.

CUNHA, M. I. da. Se "Narciso acha feio o que não é espelho", o que aprendemos com os estudos comparados em Educação? Educação UNISINOS, v. 17, n. 3, p. 232-237, dez. 2013.

FLICK, U. Uma introdução à pesquisa qualitativa. 3. ed. Porto Alegre: Bookman, 2008.

GATTI, B. A.; BARRETO, E. S. de S. (coord.). Professores do Brasil: impasses e desafios. Brasília, DF: UNESCO, 2009.

GONÇALVES, A. F. de M. Flexibilização trabalhista. 
Belo Horizonte: Mandamentos, 2007.

HARGREAVES, A. Os professores em tempos de mudança. Amadora: McgrawHill de Portugal, 1998.

MARTINS, P. L. O. Pesquisa-ensino na formação inicial de professores e a interlocução com a educação básica: princípios e metodologia. In: ROMANOWSKI, J. P.; MARTINS, P. L. O.; CARTAXO, S. R. M. (org.). Práticas de formação de professores: da Educação Básica à Educação Superior. Vol. 1. Curitiba: Champagnat, 2016. p. 1-20.

MEDEIROS, L. Revisão sistemática das teses e dissertações sobre as licenciaturas: as tendências dos estudos de estágio supervisionado.

2014. 118f. Dissertação (Mestrado em Educação) - Pontifícia Universidade Católica do Paraná (PUC/ PR), Curitiba, 2014.

MENEZES, G. G. A utilização das TIC nos processos de formação continuada e o envolvimento dos professores em comunidades de prática. Educar em Revista, n. 51, p. 283-299, mar. 2014.

MIZUKAMI, M. G. N. et. al. Escola e aprendizagem da docência: processos de investigação e formação. São Carlos, SP: EdUFSCar, 2010.

NAGY, M. C.; CYRINO, M. C. de C. T. Aprendizagens de professoras que ensinam matemática em uma comunidade de prática. Revista da FAAEBA: Educação e Contemporaneidade, v. 23, n. 41, p. 149-163, jun. 2014.

NÖRNBERG, M. Formação de professores como ação humana: reflexão e escrita sobre a prática pedagógica em contextos de ensino e pesquisa. In: CAMPO; M. A. T.; SILVA, M. R. (org.). Educação, movimentos sociais e políticas governamentais. Vol. 1. Curitiba: Appris, 2018. p. 165-178.

PRATES, S. C. Formação docente no estágio não obrigatório a partir de uma comunidade de prática. 2016. 184f. Tese (Doutorado em Educação) - Pontifícia Universidade Católica do Paraná (PUC/ PR), Curitiba, 2016.

REALI, A. M. de M. R. Políticas públicas e desenvolvimento profissional de professores: a escola como foco de formação. In: REALI, A. M. de M. R.; MIZUKAMI, M. G. N. Teorização de práticas pedagógicas: escola, universidade, pesquisa. São Carlos: EdUFSCar, 2009. p. 17-34.

ROMANOWSKI, J. P. As licenciaturas no Brasil: um balanço das teses e dissertações dos anos 90. 2002. 147f. Tese (Doutorado em Educação) - Programa de Pós-Graduação em Educação, Universidade de São Paulo (USP), São Paulo, 2002.

ROMANOWSKI, J. P. Conhecimentos pedagógicos nos cursos de licenciatura e a base comum de formação de professores In: ROMANOWSKI, J. P.; MARTINS, P. L; CARTAXO, S. R. M. Práticas de formação de professores da educação básica à educação superior. Curitiba: PucPress/Champagnat, 2016. p. 47-69.

RUSS, R. S.; SHERIN, B. L.; E SHERIN, M. G. M. What constitutes teacher learning? Teacher learning and the balance of expertise. In: GITOMER, D. E.; BELL, C. (ed.). Handbook of research on teaching: fifth edition. Washington DC: American Educational Research Association, 2016. p. 391-438.

SCHULMAN, L. S. Those who understand: knowledge growth in teaching. Educational Researcher, v. 15, n. 2, p. 4-31, 1986.

SILVA, M. da G. M. MARIALVA, W. de A. Comunidade de práticas no contexto educacional: estudo de caso da Plataforma 2.0. Educação, Formação e Tecnologias, v. 9, n. 2, p. 10-20, dez. 2016.

SZYMANSKI, H.; ALMEIDA, L. R.; PRANDINI, R. C. A. R. A entrevista na pesquisa em educação: a prática reflexiva. 2. ed. Brasília, DF: Plano, 2008.

TARDIF, M.; LESSARD, C. 0 trabalho docente: elementos para uma teoria da docência como profissão de interações humanas. Petrópolis, RJ: Vozes, 2005.

VAILLANT, D.; MARCELO, C. Ensinando a ensinar: as quatro etapas de uma aprendizagem. Curitiba: UTFPR, 2012.

VEIGA, I. P. A. (org.) Lições de Didática. 5. ed. Campinas, SP: Papirus, 2015.

WENGER, E. Communities of practice: learning, meaning and identity. New York: Cambridge University Press, 1998. 